\title{
Study on Unbalanced Development Strategy of Guangxi Tourism
}

\author{
Xin Xie $^{1}$ \\ ${ }^{1}$ Guilin Tourism University, Guilin, Guangxi, 541004
}

KEYWORDS: Guangxi Tourism; Unbalanced Development; Development Strategy

\begin{abstract}
The history of tourism development in Guangxi is short, but the growth rate is very alarming. Because economic growth is subject to tourism resources, tourism market, the level of socio-economic development of the region, regional economic structure and a series of natural and cultural factors that make tourism economy in space showing non-equilibrium features. From the geographical pattern of the macro economy, the process of industrialization in Guangxi on spatial development can be basically divided into three different economic zones, namely mature eastern zone, growth in the near-developing western areas and western areas of the original. But only as a framework and general background of Guangxi tourism spatial layout, and specializes in Guangxi economic space tourism is still rare for layout, paper tries to use methods of regional economics, quantitative indicators do describe, analyze Current Situation of Guangxi tourism unbalanced development of its causes.
\end{abstract}

\section{Introduction}

World Travel and Tourism Council tourism economic impact report issued in 1998, the use of the tourism and travel industry, said the concept that: tourism is providing transportation for tourists, tourist resort, accommodation, catering directly , shopping, leisure services and specialized for these services or direct provision of human, intellectual, and intermediary services enterprises, industries and sectors, including travel agencies, tourist hotels, tourist restaurant, designated tourist shopping malls, tourist travel company, travel fixed entertainment, travel products manufacturing enterprises, tourism promotion publishing unit, tourism websites. However, this definition does not meet the criteria of homogeneity of the product and there will be significant differences between the lodging company's products and transportation company's products. They produce products do not constitute a competitive relationship with each other, the specific features of the product is completely different, the production process is also far from. Tourism is basically a demand concept to a particular type of activity is characterized by consumers, therefore, the current definition of the tourism industry of the people, based on the consumer product instead of the product, that is to say, the starting point for the industry classification demand / consumption rather than production and supply, from the same class to meet the needs to judge that all food produced or provided to meet consumer travel in the tourism process needs, housing, transportation, travel, shopping, entertainment, etc. collection sector of goods and services or business, called the tourism industry. Obviously, in such a manner defined by the diversity and complexity of tourism demand, tourism so that people have a hard boundary clearly defined, so that we in the evaluation of the development of tourism, when it is difficult to provide an accurate quantitative indicators. Therefore, we will define the concept is clearly the most important issue of our study.

\section{Reason of Tourism Unbalanced Development}


The main difference between physical geography factor attributed to the formation of regional economic development is a natural geographical endowments, but in the context of economic globalization, new economic geography is that the main factors of regional economic imbalances are not natural and geographical endowments, but by other the influence of geographical factors. Therefore KmgmanF in explaining urban spatial development, the proposed concept of two natures, namely, first natural factor are natural geographical endowments, the second natural factors traffic and location, wherein the first Naude think nature is the inherent characteristic of the region. It is independent of human activity geographic feature and spatial relations characteristics second nature. although. Theory better explains the reasons for the formation of industrial agglomeration and regional differences in economic development, but the man-land relationship theory point of view, but stressed that the basic theory of ground. Role, and right. people. Role in regional economic development, the difference was not considered. Indeed, man's impact on nature can not be ignored, especially in the economic level and more developed era. Based on this, on the basis of Krugman two natural factors, Liu Qingchun and Wang Feng at the time of the formation of China on Regional Economic Disparity analysis, the impact of economic growth in the first orchid geographic features, namely, human capital and research and development, and $\mathrm{H}$ class elements of the differences in economic development of the empirical research through modeling analysis. Regional differences in the development of tourism as regional economic disparities embodied, formed Differences should also be considered. In the full analysis of the new economic growth theory and the theory of man-land relationship, based on the reference Krugman. Factor theory, this article will affect tourism in Guangxi regional development attributed to large differences in geographic features, where the first element is the geographic resource endowments, and the second factor is the geographical location and traffic conditions, and the third: geographic feature of human factors, including the economic level, services, policy factors. Specifically, the resource endowment is a congenital condition, is acquired immutable factors have immovable property in the geographical space, the early stages of tourism is developed on the basis of resource endowment, is the first cause of regional tourism development; and a regional position region (here mainly refers to the relationship between the distance of the major source markets), more close to the tourist market more conducive to the arrival of tourists, and the higher the degree of economic development of the tourist market, travel force is also higher. Coupled with the improvement of traffic conditions, it is based on the location of the further increase in the area of accessibility. By location and transportation together, directly affect the accessibility of the area, and then visitors spend on the road of time, money, costs have an effect. Both location and transportation make up to some extent, the impact of tourism on regional resource endowments innate differences caused by location and traffic conditions is a congenital condition is the result of acquired human activities, both of which are to promote regional tourism development incentives for the second; the human factor including the level of economic development, basic services and local policies and other factors, the human factor acquired through build. Nothing but tourism resources, constantly optimize and improve the tourism environment of tourism service facilities, humane, is promoting regional tourism development in third class incentives.

\section{Regional Tourism Unbalanced Development Theory}

In theory, any kind of industrial development between different regions is not balanced developed. Currently theorists have on regional economic unbalanced development has formed a relatively mature theory series, in which growth pole theory, point axis development theory and the theory of 
network development can be seen as a series of theory, it is a more comprehensive explanation of the development of tourism the non-equilibrium.

First, Zeng long pole theory, regional economic development is the basis for better conditions from a few areas and industry began by cultivating Diego area and some good conditions for the growth of industrial growth pole in its diffusion, under the blessing shoot action, promote the development of surrounding areas and industries. And here said growth pole, either on an empty area. Room concept, the concept of space can also be a non-industrial or business. From a regional perspective space tourism industry comprehensive high relevance and strong features, destined to its development needs superior natural resources, convenient transportation and advanced regional economy is based. Thus, as the southeast coast of Zhejiang, Jiangsu, Guangdong, Shandong and other provinces, both with more excellent tourism resource endowments, has occupied a unique geographical traffic conditions, economic support in the developed regions, based on the development of its tourism industry natural matter of course. It also makes the development of tourism in the eastern part of the early stages of growth pole for the first growing local industries. From the industry point of view, at the international level while some of the small plane has rich tourism resources of countries and regions, often depending on the tourism industry as the leading industry and take the development of strategic priorities, such as Singapore, Italy, Indonesia and other countries, that is, in the tourism industry to boost the overall economy started on the basis of continuing to build other such as finance, biotechnology, education and other services, the formation of tourism growth poles, and other industries blessing shot socio-economic model. The inland areas in the southwest Guangxi is also a growth pole for the tourism industry, economic and start shooting blessing drive other development of related industries. And in recent years, with the transformation of the economic system, sustainable development of green tourism become provinces competing for the development of the industry, from the form of the country's overall economic development point of view, for the development of tourism has entered even point axis Development Web Development stage.

Non-equilibrium theory is applied to the whole region, whether economic development or industry-specific planning, both in itself all the conditions and obtain comparative results of the surrounding area, which has a comparative advantage in areas under its regional growth pole in the consolidated area. Theory of comparative advantage is arising from international trade and division of labor, that is, according to its nuclear melon philosophy. Two excellent options, whichever weight, two bad options, whichever is light. The principle of division of labor and trade, while both the macro-regional industrial location choice and micro enterprises leading industry, its essence is according to the theory of comparative advantage. Industry for a certain area, its economy is not the start of each industry development go hand in hand, but has the potential in the region, the excellent positioning in the preferred style of leading industries, in order for the whole economy and play a guiding catalytic role.

Therefore, based on the theory of comparative advantage, the development of tourism will be the development of tourism in the region has a comparative advantage of the first developed. Initially mainly based resource endowment and location advantages, and with the development of technology will be economic and technological conditions, said two conditions is no longer the sole dominant factor determining the development of regional tourism, socio-economic conditions, infrastructure and even regional policy factors also began to affect the development of tourism. So in fact, can be attributed to the prosperity of tourism in different parts of different types based on different comparative advantages, such as tourism development according to the aid of advantages, it can be divided. Resource endowments type is Location and transportation type, resource 
endowments of regional transportation. And other types, which can be subdivided to create the resource endowments innate and acquired human resource endowment.

\section{Conclusion}

Combined with the new economic geography theory and the relationship between people and land, based on tourism factors affecting the property classification stratification factor, obtained by hierarchical regression analysis: The result of the unbalanced development of regional tourism is the natural and social interaction, but various factors different effects, and the impact of various factors on tourism also with changes in the social environment changes; natural resources from the resort on the level of tourism development is still significant, but is no longer a dominant position; a second geographic feature the traffic conditions has become an important force to promote regional tourism development, in all measurement factors affect the maximum coefficient; and section $\mathrm{H}$ of geographic features in the composition of the human factor is becoming rapidly boost regional tourism economic development of the new force can not be ignored. Transportation services and facilities which are of regional tourism economic impact coefficient two largest factors, to some extent, also shows that the role of policy factors in regional tourism development.

\section{REFERENCE:}

[1] Tu Meng. Regional Tourism Theory [J]. Social Scientists, 1994, (5): 83-88.

[2] Xue Ying. 1980 Summary of Regional Tourism Cooperation [J]. Geography, 2003, (2): 29-34.

[3] Xue Ying. Awareness of The Regional Tourism Cooperation Several Basic Problems [J]. Guilin Tourism College, 2001, (2): 26-29.

[4] Zhang Chen. Yangtze River Delta Regional Tourism Cooperation Study [J]. Tourism Resources, 2003, (5): 343-345.

[5] Wei Min, Li Guoping. Grades Process Mucosa Empirical Study of Regional Competitiveness Regional Differences [J]. Journal of Central University of Finance And Economics, 2004, (5): 41-45. 